\title{
Enterprise-Strength Internet Connectivity in the Orkney Islands
}

\author{
Wilson Nwankwo \\ Department of Computer Science \& Information Technology, Wellspring University, Benin City, Nigeria
}

\section{Email address:}

wilson.nwankwo@wellspringuniversity.edu.ng

\section{To cite this article:}

Wilson Nwankwo. Enterprise-Strength Internet Connectivity in the Orkney Islands. Science Journal of Circuits, Systems and Signal Processing. Vol. 7, No. 1, 2018, pp. 8-19. doi: 10.11648/j.cssp.20180701.12

Received: November 27, 2017; Accepted: December 6, 2017; Published: January 11, 2018

\begin{abstract}
The Internet has remained one of the most remarkable invention of the $21^{\text {st }}$ century as it has redefined the concept of globalization and turned the world into a global village where geographical and developmental limitations experienced few decades ago no longer find relevance. To this end it is possible to create solutions that could enable geographically disadvantaged locations and communities in relation to communication; to be united to their contemporaries in urban areas through information and communication networks especially the Internet. This study seeks to provide a feasible solution to the challenges of Internet access within the Orkney Islands of Kirkwall and North Ronaldsay having regard to such potential factors as: users in the surrounding communities having access to effective online business transactions, geographical terrain and location of the islands, future community development and the reliability of the communication infrastructure. To achieve its objectives this study considers available technologies and communication infrastructure that can be harnessed to attain a high speed and reliable internet connection across places located in the Orkney Islands.
\end{abstract}

Keywords: Internet Connectivity, Orkney Islands, Broadband, 4G LTE, Fibre Connections

\section{Introduction}

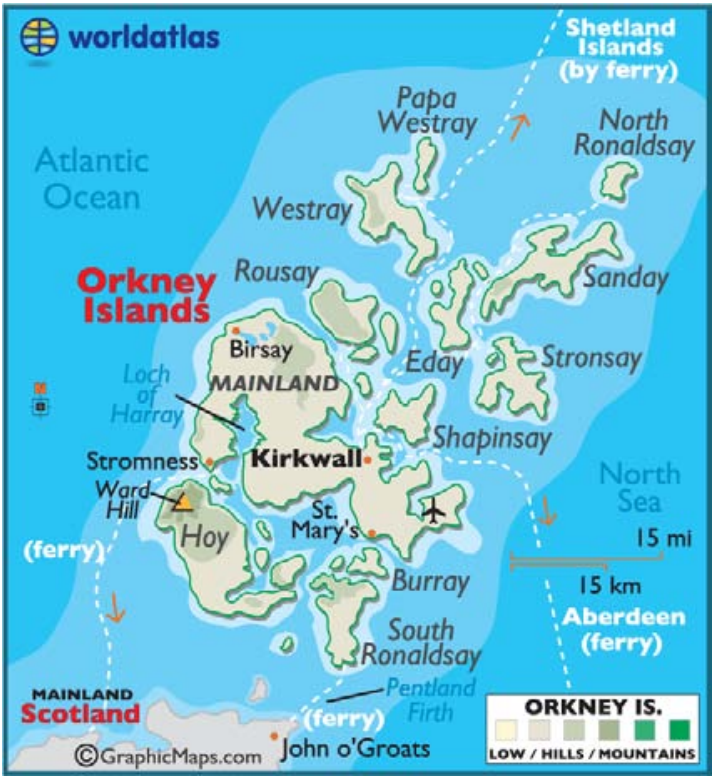

Figure 1. Map of Orkney Islands [Source: World atlas].
The Internet revolution has transformed the world into a global village economically and socially. The provision of a high speed and reliable internet connectivity to Orkney Islands would not only boost economic activities but support the harnessing and development of the myriads of resources available within the Islands.

\subsection{Aim and Objectives}

This study is aimed at providing a blueprint for consideration and review by the Orkney Islands council. The objective of this study is to identify and implement a reliable Internet solution that would support economic growth, productivity and improved global community integration in selected locations in Orkney Islands.

\subsection{Initiation and Sponsorship}

This research did not receive any specific grant from funding agencies in the public, commercial, or not-for-profit sectors.

\subsection{Scope of the Study}

This study is concerned on achieving a relatively high 
speed and reliable Internet link to support business operations at two locations in the Orkney Islands. These locations are;

i. A new business park on Pickaquoy road in Kirkwall and,

ii. A single house located at Gravity, North Ronaldsay. The emphasis is on the implementable technologies and communication infrastructure that can be used to achieved reliable and high speed connectivity to these two sites. This study does not present any detailed discussion on every device to be used; the cost estimate provided is good to serve as an insight into what is obtainable in the open market in the United Kingdom and not as final budgeted estimate.

\subsection{Expectations and Goals}

It is expected that the technologies and Infrastructure presented in this report when harnessed as discussed would achieve the ultimate goal of ensuring reliable connectivity at the two sites.

\subsection{Review of Technologies for Connectivity}

Internet connectivity can be delivered via two main technologies i.e. narrowband and broadband connections. Technologies using the narrowband e.g. dial-up links provide a slow connectivity which is not suitable for modern enterprise and related applications.

Dial-up connections

The dial-up connection is the earliest and commonest kind of connection. Dial-up allows a computer to dial a telephone number using a public switched telephone network to connect to a server at the Internet service provider's location. The existence of telephone services in Orkney Islands makes dial-up connections the commonest mode of connecting users to the internet.

Broadband connections

Broadband connections unlike their narrowband counterpart are relatively high speed connections that may or may not need the public telephone network for its deployment.

Like the dial-up, the choice of a broadband link is dependent on certain prevailing factors such as; location of the user, type of package, the cost of subscription and availability of service. For instance internet users at many remote and rural areas may not have access to fibre connections as such facilities may not exist there.

Broadband connections may be classified as:

i. Fixed broadband

ii. Wireless broadband

Fixed broadband technologies that can offer downstream speed above $256 \mathrm{kbps}$ include:

a. Digital subscriber line (DSL)

b. Cable modem

c. Fibre connection

d. Broadband over power lines (BPL)

Digital subscriber line (DSL)

DSL uses the traditional copper telephone lines installed by public switched telephone network operator across offices and homes to provide a faster internet access at a speed much higher than the dial-up. Distance from a location to a telephone exchange and the capacity/quality of the copper phone line are factors that limit the speed and availability of a DSL connection. Two most widely used variants of DSL are:

a. Asymmetrical Digital Subscriber Line (ADSL) exhibits a faster downlink speeds than its uplink using the same phone line that provides voice call service.

b. Symmetrical Digital Subscriber Line (SDSL) unlike ADSL maintains same good bandwidth in both uplink and downlink without any allowance for voice phone usage and usually ideal for businesses/users that engage in exchange of multimedia data such as video conferencing, backup services, etc.
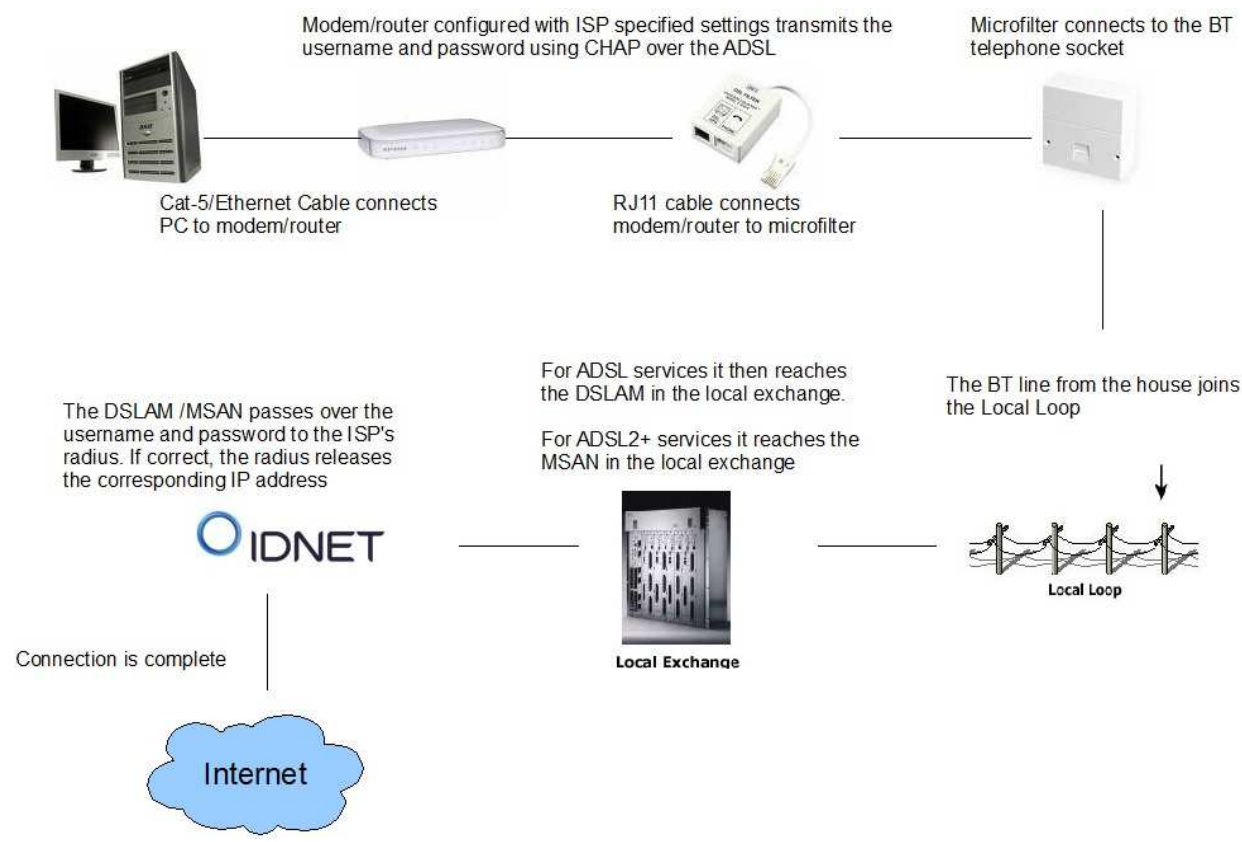

Figure 2. ADSL/ADSL2+ connection [Source: IDNET]. 
The commonest variant of DSL technology is ADSL available in Orkney Islands and accessible via 23 exchanges with British Telecom (BT) as the major provider responsible for $86 \%$ of service and two local loop unbundling (LLU) operators, Sky/Easynet and TalkTalk [1]. All the 23 exchanges support ADSL max with a downstream speed of up to $8 \mathrm{Mbps}$. The speed of the links across an exchange is dependent on demands of clients. The ADSL connection from the main Kirkwall exchange is connected to the rest of BT backhaul by a radio link via a high capacity mast in Thurso [2].

BT has upgraded most of the ADSL exchanges to ADSL2+ also known as 21st Century Network (21CN) or WBC (Wholesale Broadband Connect) a high speed broadband service which offers download speeds of up to $24 \mathrm{Mbps}$ and upload speeds of up to $1 \mathrm{Mbps}$ [3]. Unlike in ADSL where DSLAM (Digital Subscriber Line Access Multiplexer) is used in the telephone exchange, the ADSL2+ uses MSAN (Multi Service Access Node) that integrate all services onto a single box using more range of frequencies on the phone line to provide more bandwidth and reducing the variety of different equipment needed to provide services. Both ADSL and ADSL2+ services are rate-adaptive and are best efforts services shared with other clients using same Exchange and this contributes to usual fluctuation in speeds overtime. $21 \mathrm{CN} / \mathrm{WBC}$ is presently active in Kirkwall [1] but not yet activated at North Ronaldsay Exchange.

Cable modem

Cable connections unlike DSL are not limited by distance. They reach most neighbourhoods, and signal strengths don't weaken over long distances [4]. However, Cable internet providers Virgin Media are not yet offering any service around Orkney Islands and mainland Thurso.

Fibre broadband

Fibre broadband offers very high speed connectivity of up to $330 \mathrm{Mbps}$ with optical fibre using light to transmit/receive data with less susceptibility to interference, higher bandwidth, longer distance, absence of electromagnetic radiation leak from the cable unlike in DSL connections. Existing implementations include: fibre to the cabinet and fibre to the building.

Fibre to the cabinet (FTTC)

In FTTC the optic fibre runs from say a British Telecom (BT) exchange to a street cabinet that contains Broadband equipment from where it is linked to buildings and homes via BT's existing copper network.

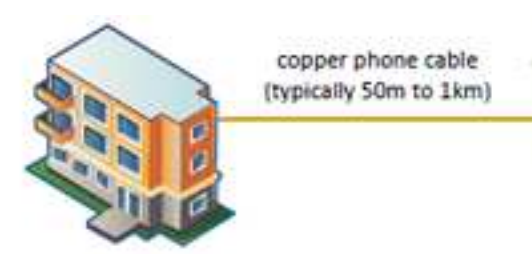

Customer Premises
(residential or business)

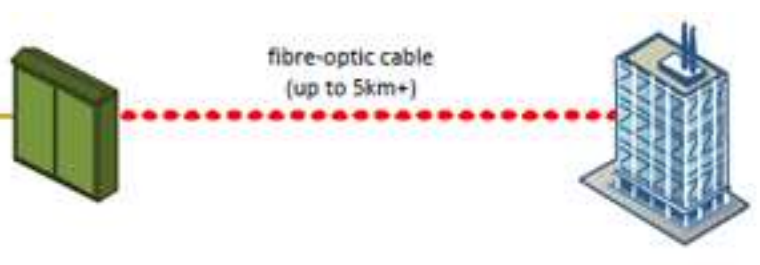

Roadside

Cabinet
Telephone Exchange

Figure 3. Fibre to the cabinet [Source: thinkbroadband.com].

Fibre to the building (FTTB)

In the Fibre to the Building option, the optic fibre connected from the exchange to a point in a shared building from where other cabling connects to offices or flats.

Fibre to the home/premises (FTTH/FTTP)
This supports a full fibre connection from the service provider's exchange to the subscriber's home/office with downstream speeds of about 330Mbps and an upstream of $30 \mathrm{Mbps}$ and beyond.

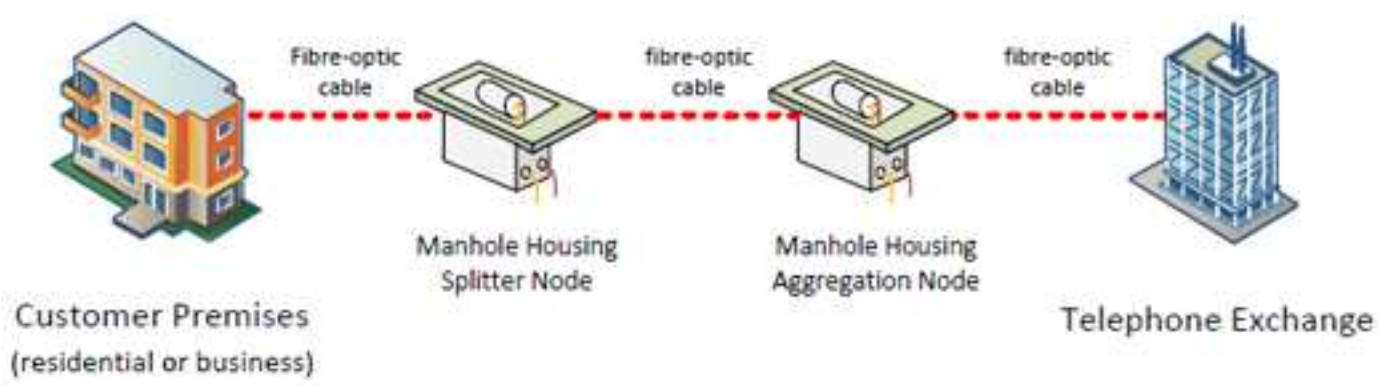

Figure 4. Fibre to the premises [source: thinkbroadband.com].

Prior to BT's link upgrade with SHEFA-2 fibre, its fibre connection in Orkney is only via microwave radio links from Scottish mainland. BT announced in September 2012 that it was to invest $£ 8$ million in a_new fibre link between the north of Scotland to Orkney and Shetland, doubling the previous fastest speeds available to $20 \mathrm{Mbps}$ and with the deal signed in march 2013 [5]. It is therefore expected that Orkney Islands' dream of having a fibre backbone would be realized soon.

Broadband Over Powerline (BOP) 
This technology though promising is not yet available anywhere around Orkney Islands.

Wireless broadband that uses microwave radio links are usually a good option in remote and sparsely populated areas where DSL or Cable modem service would be costly to provide. Two variants are used across Europe i.e.

a. Mobile broadband and

b. Fixed wireless broadband

Mobile broadband service can offer speeds of at least $256 \mathrm{kbps}$ via mobile phones, laptops, PDAs, etc. In the United Kingdom, technologies built to operate on $4 \mathrm{G}$ standards such as long term evolution (LTE) and Worldwide Interoperability for Microwave Access (WIMAX) are not uncommon.

UK broadband launched the first commercial 4G LTE service in London on 29 February 2012 [6].

EE (formerly Everything Everywhere Limited), the owner of Orange and T-Mobile networks followed suite after it received approval from Ofcom the UK regulator in August 2012 to implement the 4G mobile services [7]. EE's 4G network was later launched on October 2012 in 11 cities and is designed to cover $70 \%$ of the UK in 2013 and $98 \%$ in 2014 [8]. With $3 \mathrm{G} / 4 \mathrm{G}$ compliant USB modems (which usually has a SIM card) available from most mobile phone operators and $3 \mathrm{G}$ router an active subscriber can share a high speed internet with other users and computers in an office or home. Orkney Islands has four major mobile phone network operators but $3 \mathrm{G}$ coverage is limited, with $58.2 \%$ of Orkney's geographical area having no reliable signal [9].

Fixed wireless broadband uses fixed wireless communication links such as Microwave radios which often require a clear line of sight (LOS) between the transmitter and receiver equipment. ISPs offer these services using licensed and unlicensed devices. It has gained much acceptance over the years because of its ease of deployment, advanced technology, long distance of coverage and pricing.

Microwave connections (Wi-Fi \& WiMAX)

These provide reliable point-to-point and point-tomultipoint connectivity using radio signals in licensed and unlicensed frequencies. The radios are deployed on transmission towers/masts (ground stations) of appropriate height to link transceiver equipment located at the top of client's building or tower. They can span tens of kilometers and are scalable with base stations without significant loss of signals with throughput from $20 \mathrm{Mbps}$ to $1 \mathrm{Gbps}$ thus can support video on demand (VOD), Internet protocol television (IPTV) and Voice over internet protocol (VOIP) services. They are relatively cost effective with low maintenance cost and easy to set up provided there is a line-of-sight between the two locations to be connected. In recent times, an adaptive antenna also called smart antenna is either built-in or supplied as part of Microwave transmitters/receivers. These antennas use multiple-input/multiple-output (MIMO) techniques with orthogonal frequency modulation (OFDM) at both transmitter and receiver stations to resolve signal distortion issues thus ensuring gains in data throughput and link coverage.

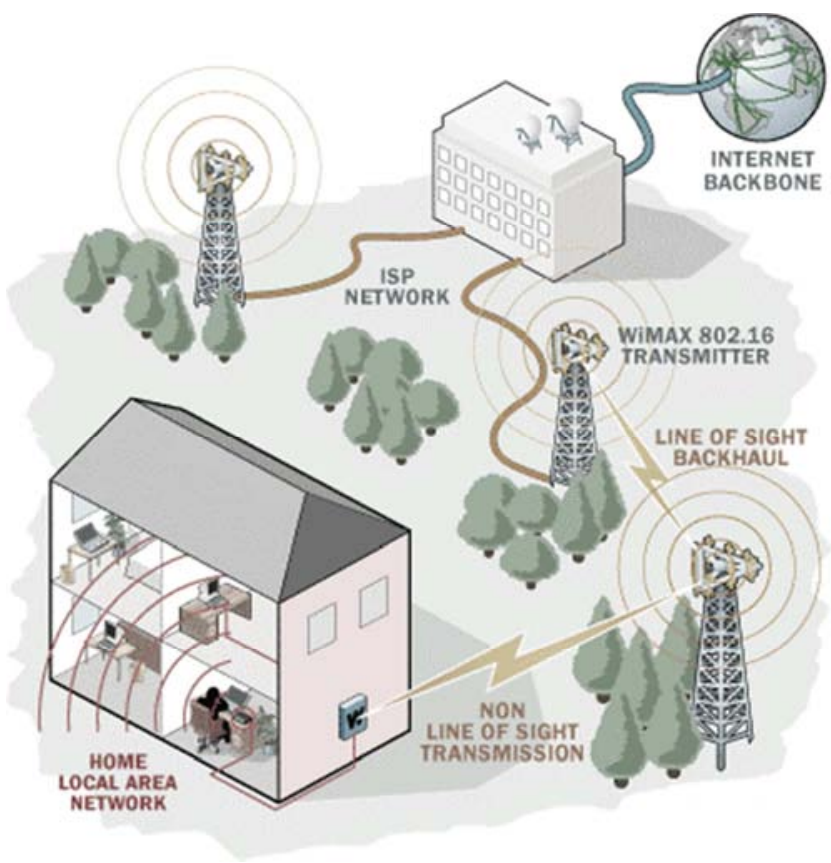

Figure 5. WiMAX connection.

In Orkney Islands, microwave links form a major crux of the available broadband service with the successful execution and maintenance of the Pathfinder North study awarded to Thus Plc (later acquired by Cable \& Wireless Worldwide Plc. $(\mathrm{C} \& \mathrm{~W})$ and now part of Vodafone in 2007 by the Scottish government to provide local authorities with leased/dedicated managed broadband services [10]. C\&W deployed a new backhaul with wireless technology using own microwave base stations independent of the BT's backbone connecting Orkney to Mainland Scotland. The Pathfinder North study has the capacity to provide reliable services to public, private establishments and third party internet service providers (ISPs) in Orkney Islands outside the local authorities for which it was initiated.

WiMAX (IEEE 802.16 Air interface specification) is very similar to WiFi but exhibits a higher speed and longer range of coverage and scalability. A WiMAX station can connect directly to the Internet using a high-bandwidth, wired connection or to another WiMAX tower using a line-of-sight, microwave link. A single WiMAX base station can cover up to 3,000 square miles [11]. WiMAX can offer non line-ofsight (NLOS) service using lower frequencies $(2-11 \mathrm{GHz})$ and line-of-sight service using higher frequencies often covering larger area. Figure 5 shows how a WiMAXcompliant service can be used to provide high speed broadband service over a large area.

According to Valongo, C\&W Plc. maintains a WiMAX Backhaul connecting Orkney to the Scottish mainland.

Satellite broadband

The Satellite provides the widest coverage with an alwayson broadband service irrespective of the terrain and geographical location and can be deployed without telephone infrastructure, wireless base stations or exchanges. Satellite Internet infrastructure use three basic components: a satellite 
in geostationary orbit (geosynchronous Earth orbit, or GEO), a number of ground stations called gateways which relay data to and from the satellite via radio waves, a VSAT (verysmall-aperture terminal) dish antenna with a transceiver and a satellite modem usually located at the consumer/customer's premises. A centralized network operations center (NOC) may be used for monitoring the satellite system. Generally, conventional Satellite-based networks are known to exhibit high latency and signal losses due to poor weather conditions.

High capacity Ka-band satellites make use of multiple narrow spot beaming technology operating at higher frequencies (26.0-40Ghz) thereby providing higher capacity, speed and consistent high data throughput over the conventional $\mathrm{Ku}$ and $\mathrm{C}$ band satellites.

Downlink speeds of up to 20Mbps and uplink speeds of up to $6 \mathrm{Mbps}$ [12] are attainable compared to ADSL's average download speed of 3.8Mbps [13] in remote areas. However, the high capacity Ka-band unlike the $\mathrm{C}$ band is greatly hampered by extreme weather conditions. According to [14] weather effects on Ka-band high capacity satellites could be mitigated via adaptive power control, adaptive modulation and coding and gateway site planning. Satellite broadband providers that provide satellite broadband solutions to business organizations and local authorities located in Orkney Islands include; Avonline broadband, Avanti Broadband, Europsat, Signal systems, IsleSat, etc.

\subsection{Assumptions}

It is assumed that the two locations/sites are ready with all necessary electrical power installations (e.g. wiring, earthing, etc.) completed.

\section{Materials and Methods}

This study adopted an "applied case study" approach. It is adjudged applied in the sense that the study is meant to solve a practical problem of the modern world, and improve the human condition. The extension to the applied research approach is drawn from the fact that the solution is designed for specific locations with unique topographic and geographical characteristics. Prior to specifying the component variables, routine survey and desk search were the major data gathering methods employed.

\subsection{Internet Connectivity in Kirkwall}

\subsubsection{Location}

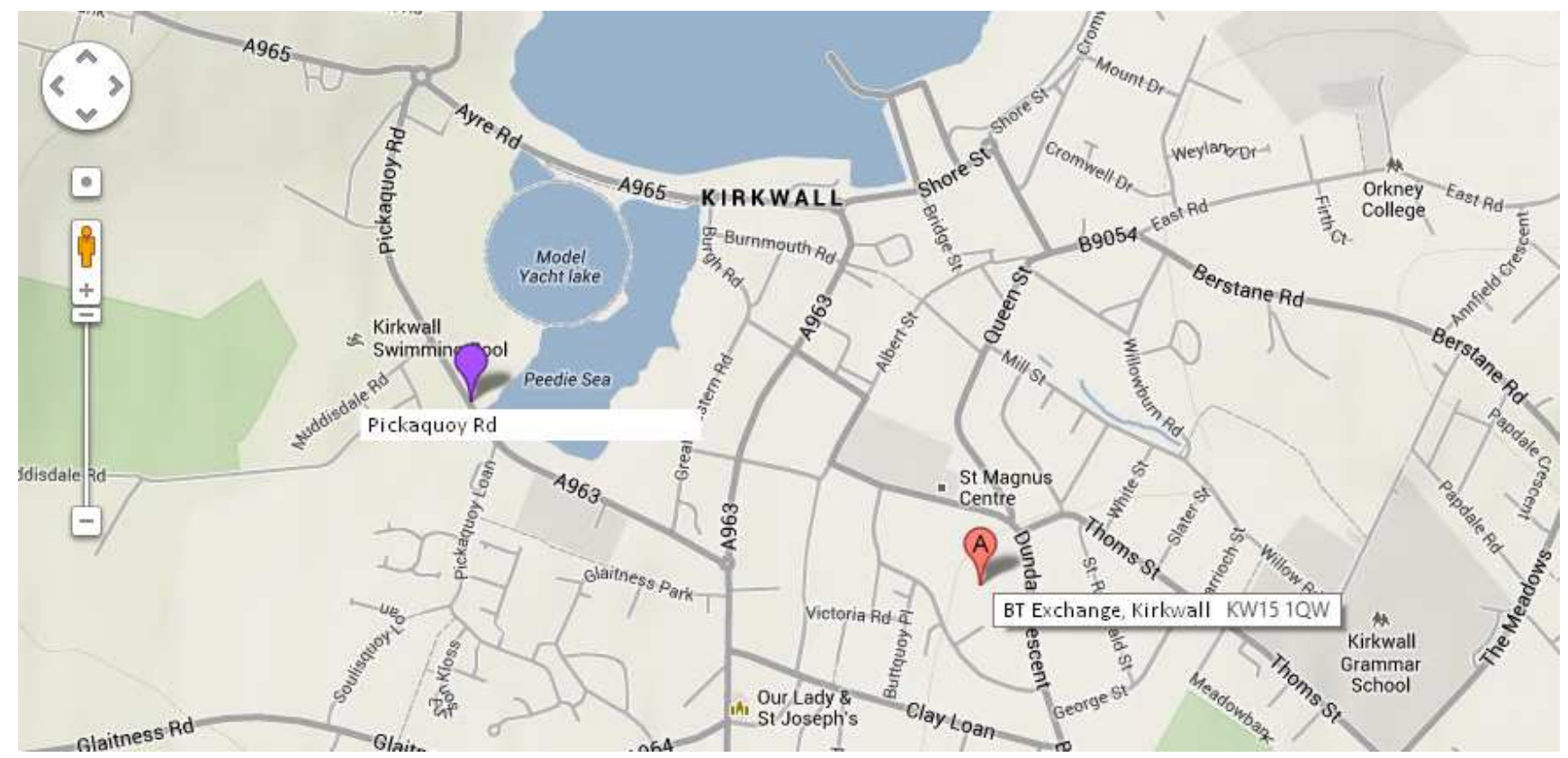

Figure 6. Map of Kirkwall showing location of Pickaquoy road and the BT Main Exchange [Source: Google maps].

Kirkwall is the largest town in the Orkney Islands. Pickaquoy road is centrally located in Kirkwall and the location of the new business park (NBP) is defined with the coordinates:

OS X (Easting) 344295

OS Y (Northing) 1011105

Latitude (WGS84) N58:59:00 (58.983442)
Longitude (WGS84) W2:58:15 (-2.970850).

OS Land Ranger HY442111I.

Nearest post code KW15 1RP.

The NBP location is about $1.485 \mathrm{~km}$ away from the BT main exchange in Kirkwall.

\subsubsection{Services and ISPs in and Around Kirkwall}

BT is a backbone provider in Kirkwall and there are also 
LLU operators like TalkTalk, SKY, EE, etc. Fibre broadband is not yet active for Kirkwall but ADSL2+/21CN services are fully activated at the exchange. High speed Satellite backhaul providers include, Broadband Everywhere, Europasat, Avonline broadband, Bentley walker, Rural broadband, Tooway connexions, etc

In addition, Pathfinder North study, managed by C\&W (now part of Vodafone) which provide leased connections up to $500 \mathrm{Mbps}$ to end-user sites using own independent wireless broadband facility.

\subsubsection{Choice of Service and Service Providers}

A business park requires a reliable and high speed connection to all business users and enterprises within it all day round. To keep up with business demands, it is estimated that the park would need a downstream speed of between $20 \mathrm{Mbps}$ and $400 \mathrm{Mbps}$ with provision for periodic bandwidth and infrastructure upgrades. As a result, a mix of broadband services is recommended. A phased approach is recommended.

i. Bonded ADSL2+/21CN solution with four separate DSL lines leased from BT, Plusnet, TalkTalk and EE and a redundant Satellite solution from any of Avonline broadband, Avanti Broadband, Europsat, Signal systems, IsleSat.

ii. Customized leased SDSL solution from C\&W

A two-phase design is considered ideal to ensure zero downtime all year round at the park.

\subsection{Location and Connectivity in North Ronaldsay}

North Ronaldsay is the northernmost island in the Orkney Islands with an area of about $6.9 \mathrm{~km}^{2}$. The Island is known to have a dynamic climate characterized by storms, snows and rain. Gravity occupies a major area in North Ronaldsay with not many residential houses scattered within it. The location to be connected to the Internet is defined by the coordinates and geographical details:

OS X (Easting) 376437

OS Y (Northing) 1054034

Latitude (WGS84) N59:22:19 (59.371925)

Longitude (WGS84) W2:24:59 (-2.416359).

OS Land Ranger HY764540.

Nearest post code KW17 2BE

Figure 7 shows the map of North Ronaldsay with Gravity and BT's Exchange

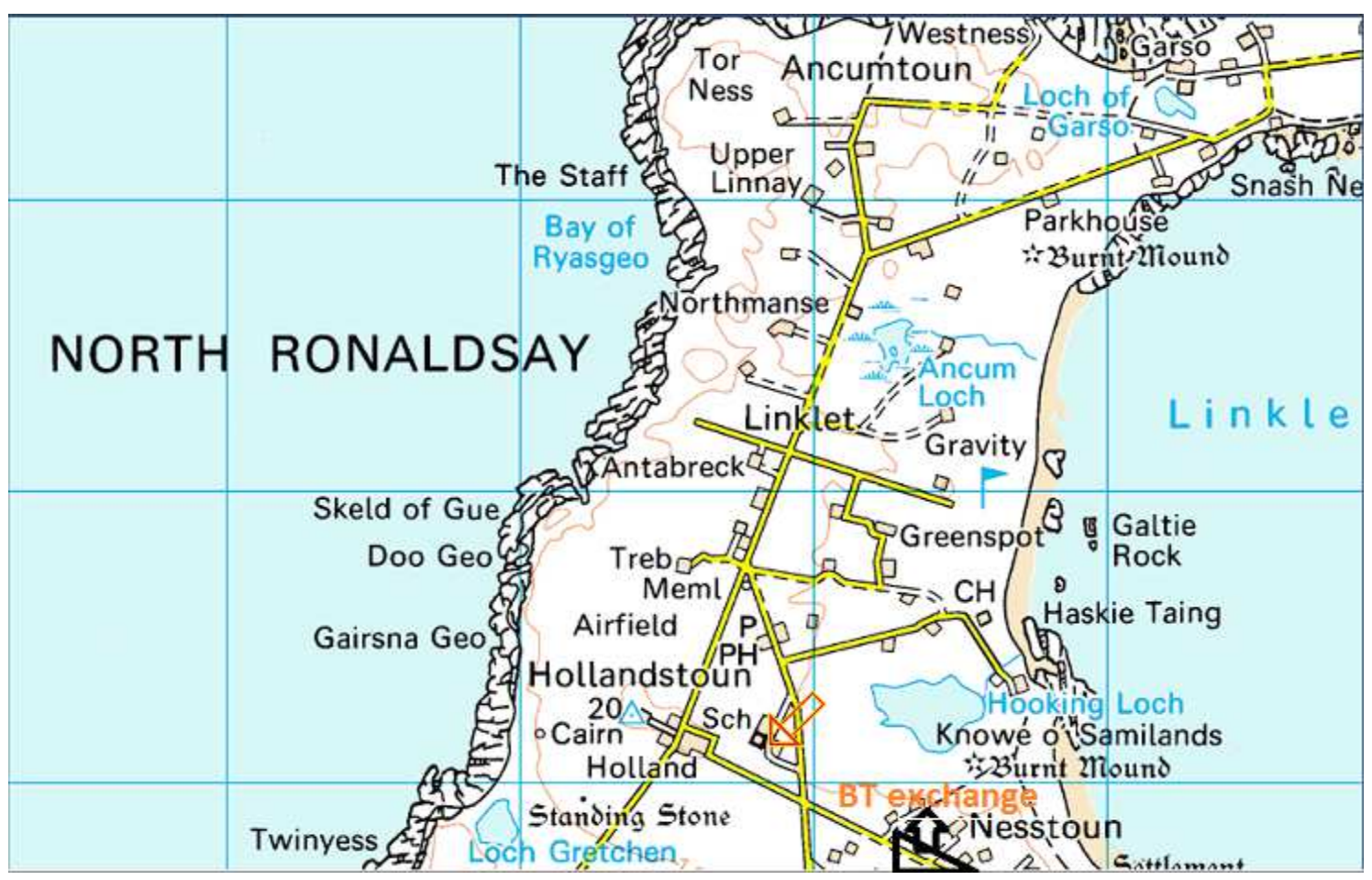

Figure 7. Map of North Ronaldsay showing Gravity and BT's Exchange [Source: Street Map].

\subsubsection{Existing Infrastructure}

North Ronaldsay has fixed telephone infrastructure provided by BT and its exchange is located at South Ness, a distance less than $1 \mathrm{~km}$ from the house at Gravity. The exchange has ADSL and ADSL max enabled but BT has not upgraded the exchange to a higher speed $21 \mathrm{CN} / \mathrm{WBC}$. BT is the sole provider of broadband services [1]. The average download speed attainable from this exchange is $512 \mathrm{kbps}$ and not good at all for a multi-user network.

\subsubsection{Choice of Service and Service Provider (s)}

As fibre broadband and BT's 21CN/WBC are not yet present in this tiny island, and considering the very low broadband speed, two solutions are proposed:

a. A wireless link established with the new business park on Pickaquoy road, Kirkwall.

b. A Satellite solution from any of Avonline broadband, Avanti Broadband, Europsat as a backup connection with a basic downstream speed of $20 \mathrm{Mbps}$ 


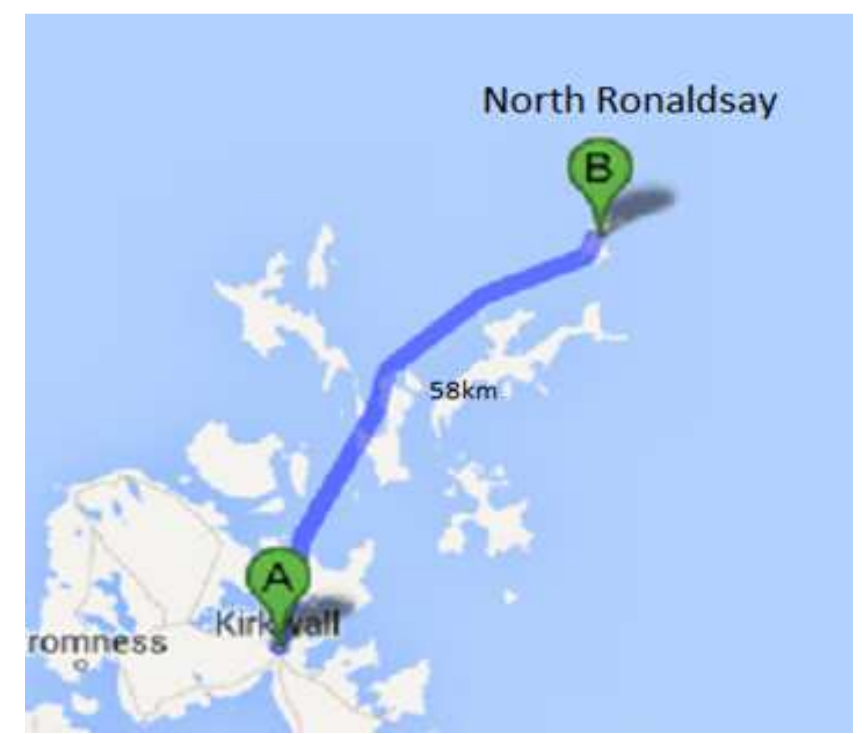

Figure 8. Distance between Kirkwall \& North Ronaldsay [source: Google maps].

\subsection{Analysis of Options}

\section{Kirkwall connectivity}

In the absence of fibre broadband in Kirkwall a cost effective solution that could be commissioned within few days is a bonded ADSL2+ solution. With this solution 2 or more ADSL2+ lines are combined using appropriate technology to provide single aggregated high speed connectivity.

The second member of the mix is a leased solution. BT and $\mathrm{C} \& \mathrm{~W}$ can provide this solution though it requires a special arrangement with any chosen provider. C\&W already has an existing Independent Wireless Infrastructure which it uses to support the Pathfinder North study that has the Scottish government and 5 local councils including Orkney Islands as sponsors. C\&W has 14 PoPs located across the councils; Highland, Moray, Orkney Islands, Shetland Islands and Argyll and Bute Councils [15] and good capacity to provide leased service for both local ISPs and end-users within the Islands. A single Microwave base station/tower (to be owned by Orkney council) at the new park would be enough to get it hooked up to C\&W's WiMAX backhaul.

The Satellite backhaul to provide a basic $20 \mathrm{Mbps} / 6 \mathrm{Mbps}$ connection is proposed and is ideal for a backup connection. Providers like Avanti, Europsat also offer customized dedicated satellite connections at higher speeds.

\section{North Ronaldsay}

In the absence of fibre broadband in North Ronaldsay and the poor ADSL solution available coupled with a limited availability of ports for distribution to subscribers at the exchange, a wireless connection to the new business park at Kirkwall would provide the house at Gravity with reliable and high speed connection.

A basic Satellite connection would also be very useful and can provide up to $20 \mathrm{Mbps} / 6 \mathrm{Mbps}$. Avanti broadband also offer a customized dedicated satellite broadband connection with higher speeds on special request.

\subsection{Results and Discussion}

\section{Kirkwall}

A bonded ADSL2+ solution offers a reliable and high speed reliable connection using multiple lines such as ADSL, ADSL2+, FTTC, HSPDA, etc. With four (4) ADSL2+ lines bonded together a reliable link (with resiliency) of at least $50 \mathrm{Mbps}$ downstream and $7.5 \mathrm{Mbps}$ upstream is attainable. This solution is cost-effective, scalable and better priced than a dedicated line of same capacity. It is also very easy to implement as the bonding solution provider need not be on site. A Satellite broadband connection would provide for redundancy and secondary resiliency thus ensuring connectivity is maintained round the clock at the park. The proposed SDSL/leased solution is meant to cater for higher future internet demands as the Park's business activities grow beyond the bonded solution in the absence of a fibre backbone though the bonded solution is also upgradable to 200Mbps downstream.

\section{North Ronaldsay}

Kirkwall is more developed and has better internet services at this time so a point-to-point microwave backhaul through Kirkwall would certainly offer a better relief. A Satellite broadband could also provide a good connection and can serve for both primary and redundancy purposes. Though North Ronaldsay exhibits unpredictable climate, a wellplanned solution is more likely to neutralize such factors.

\subsubsection{Network Design}

Kirkwall

Implementable designs of the proposed solutions are shown in figures 9, 10 and 11 respectively.

Figure 9 shows how a bonded ADSL2+ solution could be implemented. The major Network components to be deployed in the equipment room of the park are;

a. 4 Sharedband power routers or a single multichannel router that can offer a bonded throughput of at least $80 \mathrm{Mbps}$

b. 4 separate $21 \mathrm{CN} / \mathrm{ADSL} 2+$ lines leased lines from BT, EE, Plusnet and TalkTalk respectively

c. 4 units of Billion BiPAC 7800N ADSL2+ modems

d. 4 units of filtered faceplates installed on the BT's Master sockets

e. A high capacity Cisco WS-C2960S-48FPS-L Catalyst 2960S Gigabit switch

f. A $170 \mathrm{ft}$ tower to carry outdoor WiFi access points and WiMAX radios

The essence of using 4 lines with each line connecting to a separate router is to ensure resiliency and maintain connectivity when one or two lines fail. The radio tower would serve a multi- purpose function such as; support for long distance point-to-point dedicated connections and for carrying outdoor Access points that support wireless clients in the business park. The design in figure 10 is a wireless leased broadband solution from a fixed wireless provider such as Vodafone (by virtue of C\&W's infrastructure in Orkney Islands). The design is a point-to-point connection using powerful licensed full-duplex microwave radio such as 
Cablefree full outdoor microwave radio which can effectively connect two location $100 \mathrm{~km}$ apart with a throughput of about $1.6 \mathrm{Gbps}$.

Figure 11 shows a design of the satellite-based network for the new business park. The implementation of this would provide a relatively high speed internet to provide for resiliency should the primary link fail.

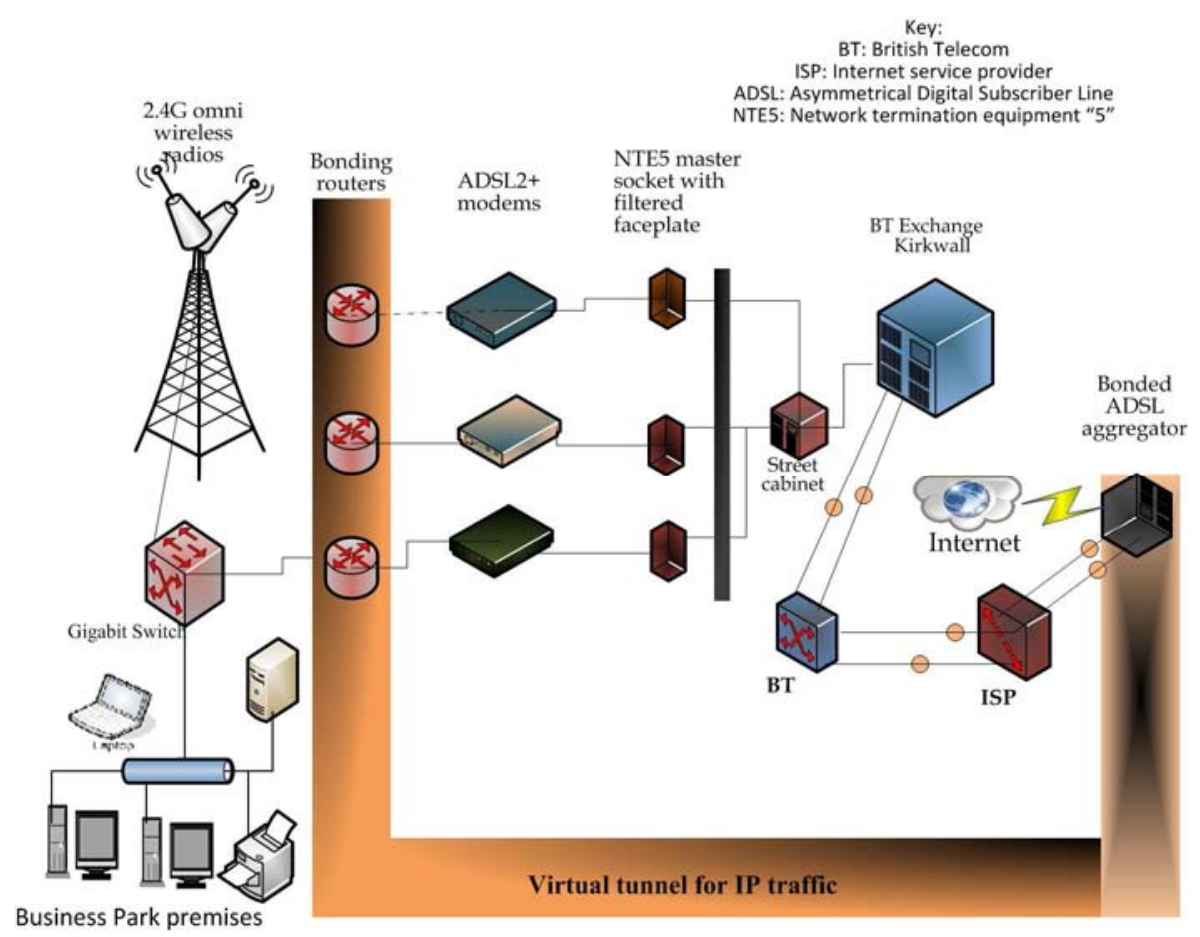

Figure 9. Implementation of a Bonded ASDL2+ solution.

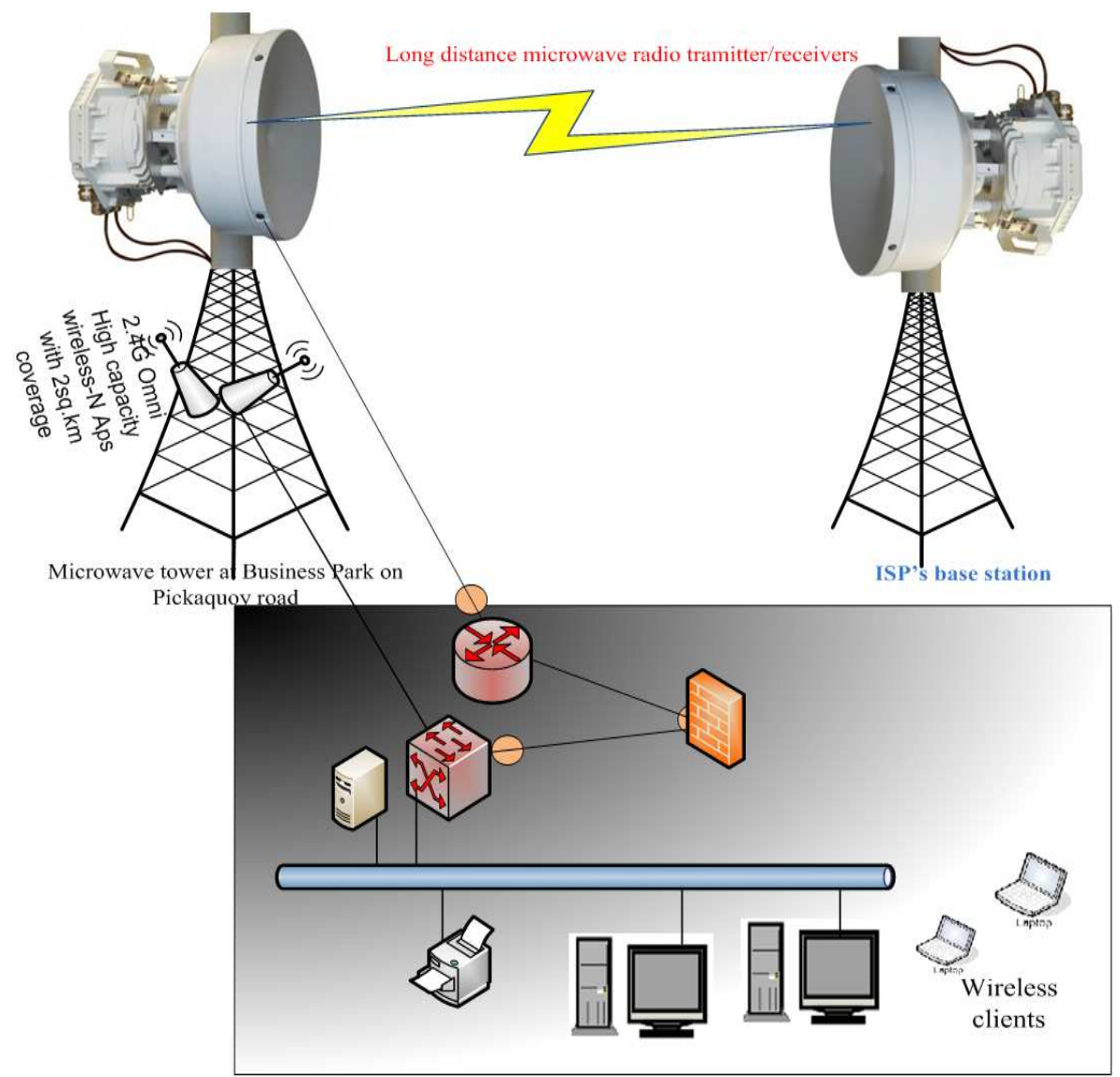

Figure 10. Implementation of a Microwave-based point-to-point leased solution. 


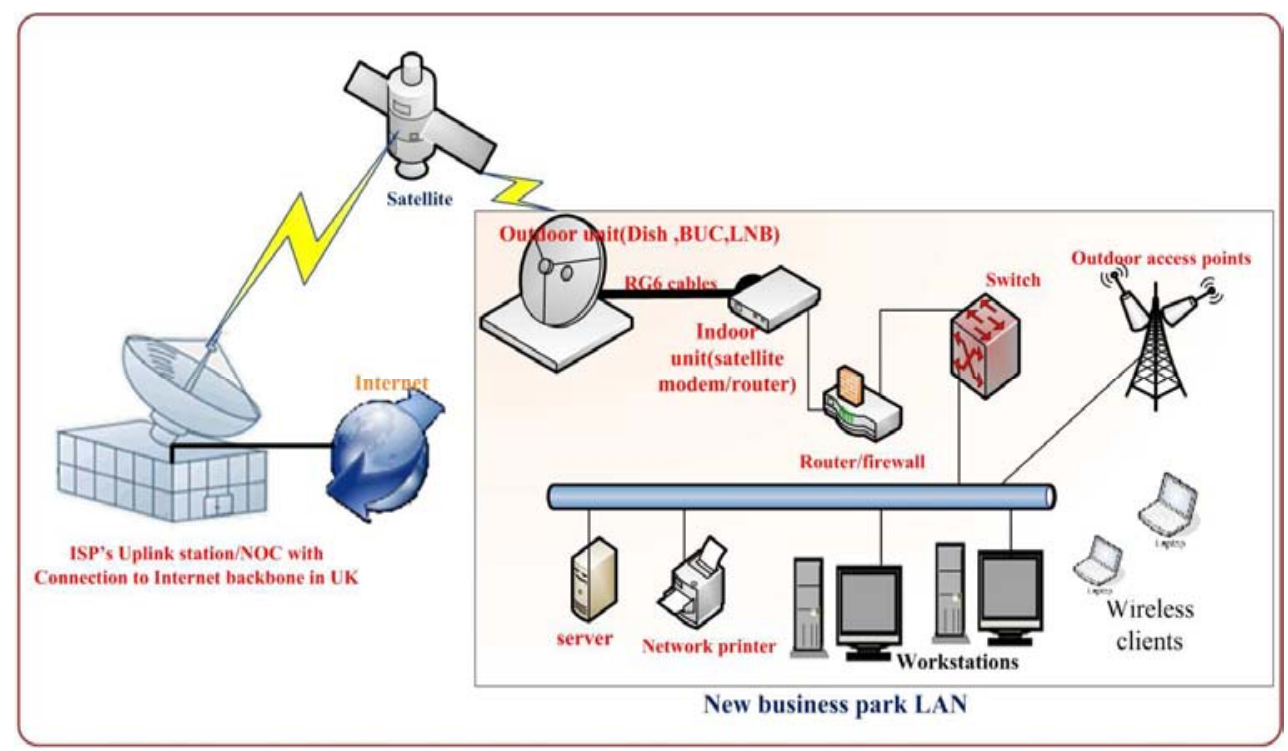

Figure 11. Satellite broadband implementation.

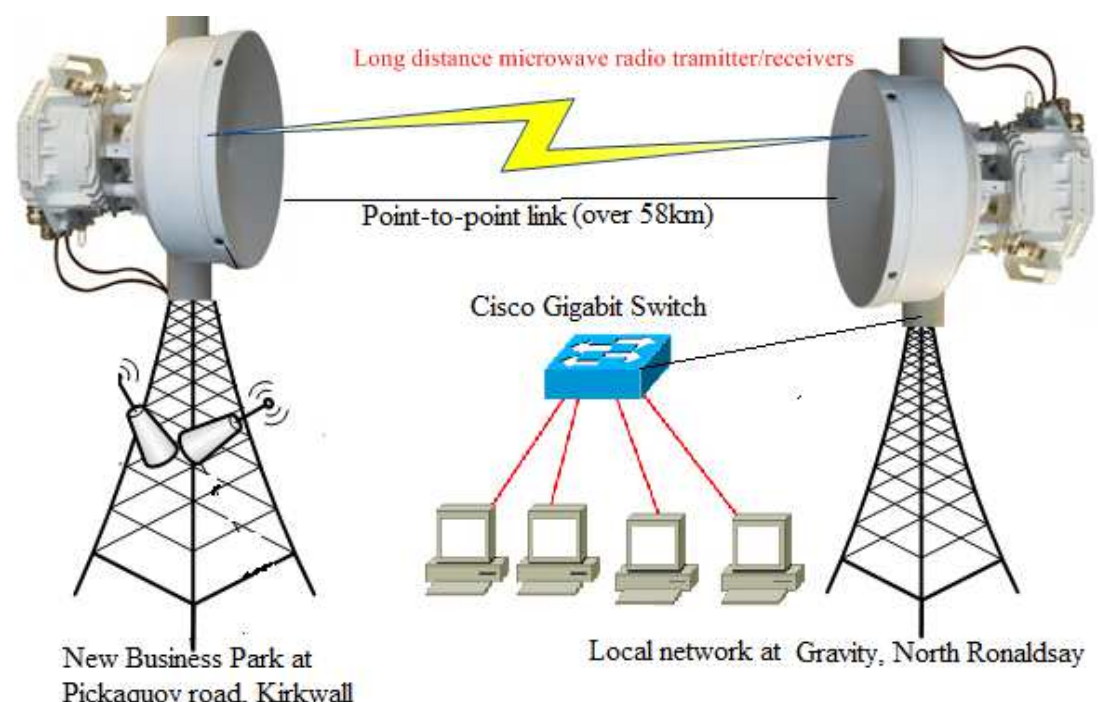

Figure 12. Point-to-point Microwave backhaul extending high speed link to Gravity from Kirkwall.

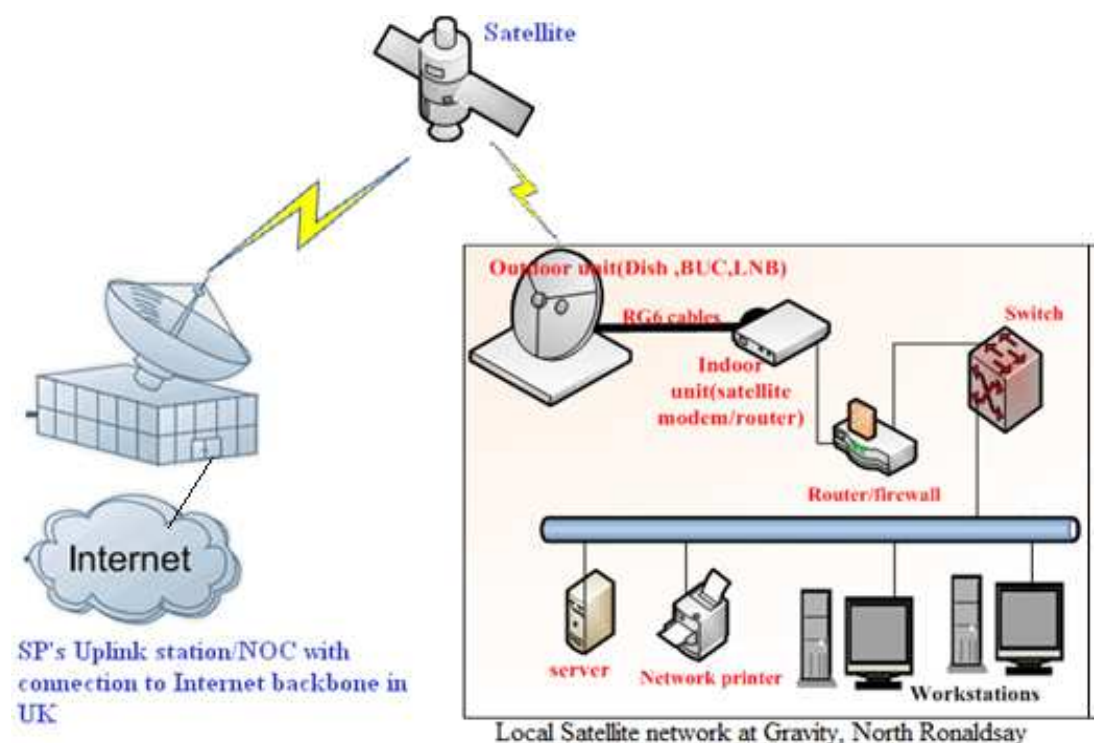

Figure 13. Satellite connection using a Ka-band solution. 


\section{North Ronaldsay}

Network designs of the proposed solutions are shown in figures 12 and 13 respectively.

The point-to-point link shown in figure 12 is designed to relay a high speed internet provisioned at the new business park in Kirkwall to a location at Gravity. Powerful microwave radios that can provide LOS and NLOS connection over $90 \mathrm{~km}$ are used.

\subsubsection{Project Cost Estimation}

The project cost estimation process is a realistic evaluation of the cost of a given project based on known facts about a project of similar requirements including resources, constraints, and the environment. The cost estimation process often commences by breaking the project into components. A project component may include a design, engineering, development, fabrication, or work packages contained in the work breakdown structure. Estimation is a very important function of a project management team and may involve any or all of the following classes:

a. Members of the project management office (where such exists);

b. Selected members from functional departments; and

c. Contractors/experts (where applicable).

The team tries to identify tasks in the project that are similar to those undertaken in the recent past. Two approaches are available for estimation: the developmental approach, and off-the-shelf (OTS) approach. The developmental approach is akin to the "bottom-up" approach whereby the cost of each project component is determined without reference to any known or previous project estimate/cost. In this study, we employed the OTS approach using the market prices of the various components that are to be deployed.

Kirkwall

The cost estimates are given in UK pounds sterling. The cost estimates are different for each proposed solution. The estimated cost of materials for the various technology options are shown in Table 1-4. The estimated costs in the tables below are extracted from some known individual equipment provider/seller websites. It should be noted that the estimates are for guidance only as changes in such prices may change without notice as well as the technology in question.

Bonded solution

Table 1 shows the bill of materials for executing a bonded solution.

Table 1. Bill of materials for bonded solution.

\begin{tabular}{llll}
\hline Description & $\begin{array}{l}\text { Units } \\
\text { required }\end{array}$ & $\begin{array}{l}\text { Unit } \\
\text { cost (£) }\end{array}$ & $\begin{array}{l}\text { Total } \\
(\mathfrak{f})\end{array}$ \\
\hline Billion BiPAC 7800N ADSL2+ modems & 4 & 105.00 & 440.00 \\
Fixed Phone line rental per month & 4 & 16.00 & 64.00 \\
Filtered faceplates & 4 & 6.50 & 26.00 \\
48-port Cisco Enterprise Gigabit Switch & 1 & 2045.00 & 2045.00 \\
Ubiquiti Outdoor access points & 2 & 120.00 & 240.00 \\
170ft steel tower & 1 & 4800.00 & 4800.00 \\
\hline
\end{tabular}

The details in Table 2 are sourced from Cable.co.uk and some individual providers' websites respectively.

Table 3 shows estimated cost of additional cost for bonding service from some bonded service providers.

Table 2. Estimated cost for Fixed broadband subscription.

\begin{tabular}{llllll}
\hline Provider & Monthly usage & Contract period & Downstream speed (mbps) & $\begin{array}{l}\text { Upstream Speed } \\
\text { (mbps) }\end{array}$ & $\begin{array}{l}\text { Upfront/setup fees } \\
\text { (one-off) (£) }\end{array}$ \\
\hline TalkTalk & Unlimited & 18 months & $13-24$ & $1.5-10$ & 30.00 \\
EE & Unlimited & 18 months & $13-24$ & $1.5-10$ & 10.00 \\
Plusnet & Unlimited & 12 months & $14-38$ & $1.3-7$ & 0.00 \\
BT & Unlimited & 12 months & $13-24$ & $1-10$ & 5.99 \\
\hline
\end{tabular}

Table 3. Additional cost for bonded solution.

\begin{tabular}{lllll}
\hline Provider & $\begin{array}{l}\text { Monthly data transfer } \\
\text { allowed }\end{array}$ & Contract period & Number of lines allowed & Setup/Hardware fees (£) \\
\hline Eclipse & Unlimited & 12 months & 4 & 200.00 \\
Broadbandbuyer & Unlimited & 12 months & 4 & 0.00 \\
Enrick IT Networks & Unlimited & 12 months & $>4$ & 1454.03 \\
SharedBand & 250GB & 12 months & 4 & 655.00 \\
\hline
\end{tabular}

Table 4. Satellite broadband subscription estimates.

\begin{tabular}{|c|c|c|c|c|c|c|}
\hline Provider & Monthly usage & $\begin{array}{l}\text { Contract period } \\
\text { (months) }\end{array}$ & $\begin{array}{l}\text { Downstream } \\
\text { speed (mbps) }\end{array}$ & $\begin{array}{l}\text { Upstream } \\
\text { Speed (mbps) } \\
\end{array}$ & $\begin{array}{l}\text { Setup/hardware } \\
\text { fees }(£)\end{array}$ & $\begin{array}{l}\text { Average monthly } \\
\text { fees (£) }\end{array}$ \\
\hline Avonline broadband & 100GB (unlimited off-peak) & 24 & 20 & 6 & 509.95 & 287.95 \\
\hline Tooway max & Unlimited & 24 & 20 & 6 & 430.00 & 79.95 \\
\hline Europsat & $50 \mathrm{~GB}$ & 24 & 20 & 6 & 429.80 & 74.90 \\
\hline Bently Walker & $175 \mathrm{~GB}$ & 24 & 20 & 6 & 0.00 & 508.05 \\
\hline
\end{tabular}

North Ronaldsay

The estimation process here is similar to that in the case of Kirkwall. However, in some cases, equipment would only be available as part of the contract.

Estimated cost of a Point-to-point solution 
Table 5 shows the bill of materials for the deployment of a point-to-point (PTP) connection. Like in the previous case, the estimates are expressed in UK pound sterling.

Table 5. Bill of materials for point-to-point connection.

\begin{tabular}{lll}
\hline Description & Units & Unit cost (£) \\
\hline 24-port Cisco Enterprise Gigabit Switch & 1 & 1045.00 \\
Ubiquiti Outdoor access points & 1 & 120.00 \\
170ft steel tower & 1 & 4800.00 \\
CableFree Licensed full duplex Microwave radio, dual ODU & 2 & 1045.00 \\
\hline
\end{tabular}

Table 6. Basic Satellite broadband estimates.

\begin{tabular}{|c|c|c|c|c|c|c|}
\hline Provider & Monthly usage & $\begin{array}{l}\text { Contract } \\
\text { period }\end{array}$ & $\begin{array}{l}\text { Downstream } \\
\text { speed (mbps) }\end{array}$ & $\begin{array}{l}\text { Upstream Speed } \\
\text { (mbps) }\end{array}$ & $\begin{array}{l}\text { Setup/hardware } \\
\text { fees }(£)\end{array}$ & $\begin{array}{l}\text { Avg. monthly } \\
\text { fees (£) }\end{array}$ \\
\hline Avonline broadband & 100GB (unlimited off-peak) & 24 months & 20 & 6 & 509.95 & 287.95 \\
\hline Tooway- max & Unlimited & 24 months & 20 & 6 & 430.00 & 79.95 \\
\hline Europsat & $50 \mathrm{~GB}$ & 24 months & 20 & 6 & 429.80 & 74.90 \\
\hline Bently Walker & $175 \mathrm{~GB}$ & 24 months & 20 & 6 & 0.00 & 508.05 \\
\hline
\end{tabular}

\subsubsection{Implementation of Chosen Technologies}

First and foremost, a steering committee and a project team would be set up to see the above designs realized. The function of the steering committee would be to offer support, guidance and monitor the project implementation progresses. The project implementation team headed by a project manager would harness individual expertise and resources available to procure, install and commission the project. Implementation of a point-to-point is usually straightforward. Prior to installation, a proper site survey should be conducted and necessary adjustments made and documented. Technologies available and providers should be reviewed to get the best solution available.

\section{Conclusion}

This study presented a concise framework and costeffective solution for establishing reliable and high speed connections across two locations/sites in Orkney Islands. Existing technologies and infrastructure were reviewed to identify practicable solutions such as:

Satellite broadband, Wireless broadband using WiMax/WiFi (point-to-point/point-to-multipoint) and bonded ADSL2+ solutions. Fibre broadband and Broadband over power lines are two good technologies that would have provided a reasonable alternative however, both are unavailable and would require a heavy investment possibly through government partnership with the relevant providers and authorities across Orkney Islands. BT has an ongoing fibre project across the Islands and the proposed solutions if implemented are upgradable when BT's fibre is commissioned.

Three solutions proposed for one - Kirkwall's new business park on Pickaquoy road are;

a. Bonded ADSL2+ solution,

b. A satellite backhaul to serve as a redundant link and

c. A dedicated/leased service to be provided by a major independent service provider such as Vodafone.

Owing to lack of upgraded telecommunications infrastructure at North Ronaldsay and its unpredictable weather, a bonded ADSL solution wouldn't give good results hence a point-to-point wireless connection backed up by a satellite backhaul are considered reliable enough to offer high connectivity speeds.

Regarding provisioning a dedicated internet connection (SDSL) at the two locations, consultations with key telecoms and internet providers are necessary due to the high investment requirements and special provisions that need to be made by the service providers.

For the location at Gravity, North Ronaldsay, two solutions are proposed: a point-to-point connection to the new business park's high speed connection and a Ka-band-based satellite solution. Thus with a sophisticated connection at Kirkwall, the location at Gravity could be made to have access to a high speed internet via a wireless connection using a powerful microwave radio that can have a $100 \%$ throughput above the $58 \mathrm{~km}$ distance.

\section{References}

[1] Sam Knows, North Ronaldsay Exchange, Broadband and Cable Availability in North Ronaldsay [online], 2013; Available http://www.samknows.com/broadband/exchange/NSNRS> [Accessed 9 December, 2016].

[2] Valongo, K. (2008.) A study of the pervasiveness of broadband internet access in Orkney-A remote Island environment. [online image] Available at: $<\mathrm{http} / /$ www.acornconcepts.com/broadband/dissertation\%201a test $\% 20$ with\%20appendix.pdf $>$ [Accessed 5 November 2017].

[3] IDNET (n.d.) ASDL2+ [online] Available at:<http://www.idnet.net/support/guides/basics/ads12plus.php > [Accessed 3 November 2013].

[4] Franklin, C. (n.d.) How DSL works [online] Available at: $<$ http://www.howstuffworks.com/ds14.htm> [Accessed 10 November 2013].

[5] McCaskill, S. (2013). BT Signs £146m Scottish Highlands And Islands Broadband Deal [online] Available at: <http://www.techweekeurope.co.uk/news/highlands-andislands-broadband-bt-111354> [Accessed: 3 November 2017]. 
[6] Jowitt, T. (2012). 4G LTE Network From UK Broadband Goes Live In London [online] Available at: $<$ http://www.techweekeurope.co.uk/news/4g-lte-networkfrom-uk-broadband-goes- live-in-london-63676>[Accessed 3 November 2016].

[7] Beavis, G. (2012). Everything Everywhere gets 4G go ahead. [online] Available at: <http://www.techradar.com/news/phoneand-communications/mobile-phones/everything-everywheregets-4g-go-ahead-1092881> [Accessed 20 November 2013].

[8] Tripathi, S. (2012). It's live! EE launches superfast 4G mobile network in 10cities [online] Available at: $<$ http://www.londonlovesbusiness.com/business-news/itslive-ee-launches-superfast- $\quad 4 \mathrm{~g}$-mobile-network-in-10cities/3791.article> [Accessed 7 November 2017].

[9] Orkney Islands Council (2012). Written Evidence from Orkney Islands council [online] Available at: $<$ http://www.scottish.parliament.uk/S4 InfrastructureandCapit alInvestmentCommittee/Inquiries/Orkney_Islands_Council.pd f $>$ [Accessed 7 November 2015].
[10] Macdonald, M. (2011). Pathfinder Evaluation study [image online] Available at: <www.scotland.gov.uk/Resource/Doc/342377/0113933.pdf> [Accessed 10 December 2016].

[11] Brain \& Grabianowski (2013) Next Generation Broadband in the Highlands and Islands of Scotland.

[12] EuropeSat (n.d.) Compare Networks [online] Available at: $<$ http://www.europasat.com/product-chooser/comparenetworks/> [Accessed 3 November 2013].

[13] Samknows (2013). Broadband availability details for Orkney Islands [online] Available at:

$<$ http://www.samknows.com/county/Orkney+Islands $>$ [Accessed 9 December, 2013].

[14] Petranovich, J. (2012). Mitigating the effects of weather on Ka-band high capacity satellites [online image] Available at: $<$ www.viasat.com/files/assets/.

[15] Highlands \& Islands Enterprise (2012) Creating A Digital Region [online] Available at: < www.hie.co.uk/digital $>$ [Accessed 3 November 2017]. 